\title{
Teatro dialético como prática pedagógica em comunidade
}

\author{
Dialectical theatre as pedagogical community practice
}

por Aline Porto Quites e Márcia Pompeo Nogueira

\section{RESUMO}

0 presente trabalho estuda a perspectiva brechtiana num contexto teatral comunitário, mais precisamente investiga aspectos do teatro dialético presentes no processo criativo da peça Relações em conflito. A peça, de um lado, foi criada com o objetivo de gerar um trabalho cênico no qual os integrantes do grupo de teatro da comunidade da Tapera pudessem se reconhecer e refletir de forma mais aprofundada sobre as relações e os processos que modificam sua comunidade. De outro lado, a montagem era uma oportunidade para os facilitadores, integrantes do grupo Fofa, participarem de um processo conjunto que partisse de uma investigação dos interesses e características da comunidade e gerasse uma criação teatral. Dessa forma, o processo aqui analisado foi construído a partir da interação entre estes dois grupos. Partindo da apresentação de nosso entendimento do teatro brechtiano, envolvendo os conceitos de teatro épico, contradição, conflito e distanciamento, neste artigo são analisados os aspectos brechtianos presentes nas diferentes fases do processo criativo de Relações em conflito, que inclui: a fase de pesquisa na comunidade; a fase de construção da dramaturgia e montagem; e a fase das apresentações. Complementarmente, apontamos a proximidade do teatro dialético com o pensamento de Paulo Freire e a idéia de conscientização e dialogismo. Os dois autores fundamentam a análise dos personagens e suas ações, e do significado da peça na comunidade.

Palavras-chave Brecht; Contradições; Comunidade

\section{ABSTRACT}

This paper studies a Brechtian approach in a community theatre context, more precisely it investigates the dialectical theatre aspects present in the creative process of the play Relações em Conflito (Relationships in Conflict). The play, in the one hand, was created with the aim of generating a theatrical work in which members of a community theater group from Tapera [in Florianópolis, Southern Brazil] could recognize and reflect in a deeper way the relationships and the processes that change their community. On the other hand, the performance was an opportunity for facilitators, members of a group called Fofa, to participate in a joint process that started from an investigation of the characteristics and interests of the community members that could generate a theatrical performance. Thus, the process analyzed here was constructed from an interaction between these two groups. Based on the presentation of our understanding of Brechtian theater, involving the concepts of epic theater, contradiction, conflict and distance effect, this paper analyzes the Brechtian aspects observed in different stages of the creative process of Relações em Conflito, which includes: the research phase in the community, the evising process and the mounting the the play; and the presentations phase. In addition, we point out the 


\section{Artes Cênicas}

proximity of the dialectical theater and Paulo Freire's thinking and the idea of awareness and dialogism. The analysis of characters and their actions, as well the meaning of the play within the community, were based in both authors.

Keywords Brecht; Contradictions; Community 


\section{Apresentação}

0 trabalho que segue estuda a perspectiva brechtiana no processo criativo da peça Relações em Conflito (dramaturgia coletiva, parcialmente inspirada na peça Woyze$c k$, de Georg Büchner), desenvolvido de forma integrada pelo grupo Chacoalhão (um grupo de teatro formado por crianças e adolescentes, que já existia antes da intervenção do FOFA e era dirigido pelo então adolescente Filipe Ferreira, que ainda hoje se mantém no projeto), da comunidade da Tapera, Florianópolis, e pelo Núcleo de Formação de Facilitadores (FOFA) da UDESC, no ano de 2010. 0 processo envolveu três fases: pesquisa na comunidade; construção da dramaturgia e montagem; apresentações.

\section{Primeiro semestre (2009-2) - fase preparatória: pesquisa na comunidade}

Em 2009, o FOFA visitou o bairro Tapera. Nesse mesmo ano esses alunos fizeram uma oficina teatral na UDESC, ministrada pelo FOFA. Nessas oficinas, quando foi feito um grande painel, representando a Tapera, os alunos foram estimulados a desenhar histórias reais e fictícias que teriam acontecido neste cenário. Todas as histórias apresentadas traziam conflitos que quase sempre acabavam com violência'. Viu-se então a pertinência em se fazer um trabalho teatral que envolvesse esses temas, levando os alunos a refletirem sobre esses personagens, suas histórias e suas razões, de modo que se visse de maneira mais distanciada e crítica sua comunidade e principalmente a escola, ao mesmo tempo em que se percebesse que uma mesma história pode ter diferentes desfechos.

Apesar do teatro de Brecht ter sido base da investigação do teatro na Tapera, a dramaturgia foi inédita, criada pelo grupo. Por isso nosso trabalho pretendeu dialogar com a Companhia do Latão, de São Paulo, cujas publicações, organizadas por Sérgio de Carvalho, serviram também como referencial teórico, bem como os protocolos das oficinas ministradas pelo mesmo para os membros do FOFA. Fora, aliás, o próprio Sérgio de Carvalho quem sugeriu a leitura de Woyzeck, após constatar inúmeras coincidências entre os contextos desta dramaturgia e da Tapera, principalmente o fato do texto de Büchner retratar uma base militar interferindo na vida da comunidade, assim como na Tapera, onde se situa a Base Aérea de Florianópolis. Ele afirma, ao falar sobre dramaturgia brasileira contemporânea, que

1 Sérgio de Carvalho, professor da USP e diretor da Cia. do Latão, SP, diz que, embora o depoimento não seja uma forma em si ruim, corre o risco de conferir estatuto de pseudo-verdade a uma experiência muito particular (Carvalho, 2009, p. 76). Por isso, o FOFA optou por ouvir histórias de verdade e de mentira, sem que se revelassem quais as verdadeiras e quais as inventadas. 
(...) para refletir sobre "nossas coisas" os temas podem ser estrangeiros. Além de conectar a experiência local com o tempo mundial, isso pode gerar uma problematização no fato de que, ao herdarmos formas estéticas européias, colocadas como universais, criamos sentidos diferentes ao adaptá-las para o contexto brasileiro (Carvalho, 2009, p. 55-56).

Desta forma, as leituras desses dois autores alemães, da metade do século XIX e primeira metade do século XX, nortearam a montagem teatral no bairro Tapera, no ano de 2010.

\section{Segundo e terceiro semestre (2010) - execução: construção da dramaturgia, montagem e apresentações}

0 objetivo geral era criar um trabalho cênico no qual os alunos pudessem se reconhecer e refletir de forma mais aprofundada sobre as relações entre as pessoas e os processos que modificam sua comunidade. Também foi pesquisado e discutido com a turma o tema bullying, vindo de uma das histórias trazidas, a partir do qual foram coletadas eventuais histórias, vivenciadas pelos alunos. Tudo isso contribuiu com a dramaturgia do trabalho. 0 resultado culminou na estréia da peça teatral $R e$ lações em Conflito, a 13 de junho de 2010, na Oficina Intensiva (encontro de grupos de teatro em comunidade), no Centro de Artes da UDESC, sob a direção geral de Márcia Pompeo Nogueira. Paralelamente à história de bullying, o universo adulto da peça se inspirou em passagens da peça Woyzeck, de Georg Büchner.

A história de Relações em Conflito se passa em um bairro de periferia no qual está instalada uma base militar. Foi criada com referência no bairro Tapera, mas poderia ocorrer em qualquer outro lugar do país. Trata-se, assim como os trabalhos da Cia. do Latão, de uma espécie de leitura da tradição brechtiana aplicada ao contexto do Brasil contemporâneo.

Para isso realizamos várias apresentações ao longo do semestre, em diferentes contextos e locais. Toda vez que alguém não podia comparecer, era substituído por outro integrante, que ensaiava seu papel. Procuramos fazer com que a soma dessas diferentes interpretações contribuísse na criação do tipo representado, como propunha Brecht em seu teatro. Para Brecht (1963) os atores deviam trocar os papéis entre si nos ensaios, de modo que todas as personagens tivessem possibilidade de receber umas das outras tudo aquilo de que necessitavam reciprocamente. Convém, igualmente, que os atores vejam suas personagens serem imitadas por outrem, ou que as vejam com outras configurações. Assim, quando a personagem surge entre as outras, a sua estrutura já foi submetida a inúmeras intervenções; 0 ator deverá, então, estudar todas as conjecturas que o texto tiver suscitado. Mas é, sobretudo, em função do tratamento que as outras personagens Ihe dispensam que fica conhecendo melhor a sua personagem. Isso também ocorreu em dias de 
aula, em momento de descontração, em que os alunos experimentavam fazer os personagens que nunca tinham feito, brincando com as diferenças provocadas pelos diferentes tipos físicos e gêneros.

Em Relações em conflito é a situação econômica que gera toda a história do protagonista Francisco. Em troca de algum dinheiro para sustentar a família, submetese a um experimento científico no qual só lhe é permitido comer ervilhas². Por causa disso enlouquece e sua loucura o torna segregado pelas pessoas de sua comunidade. Conseqüentemente sua filha também passa a ser discriminada e sofrer bullying na escola. Após sofrer uma humilhação, Francisco perde totalmente a capacidade de medir seus atos e acaba surrando um garoto que ameaça agredir sua filha.

0 personagem Francisco era representado alternadamente por dois atores que trocavam entre si, diante do público, não apenas o figurino, mas também a postura e os gestos. Isto se trata de um efeito de distanciamento, fazendo com que o público não acompanhe cegamente a trajetória de um personagem, nem se identifique com ele.

\section{Perspectiva brechtiana}

Quando se decidiu pela montagem de Relações em Conflito, a proposta era realizar, no contexto da comunidade, um espetáculo teatral com personagens dialéticos, sem maniqueísmo, com distanciamento brechtiano, partindo de uma dramaturgia coletiva entre alunos, estagiários e membros do FOFA, com cuja pesquisa o estágio também contribuiria. Por isso não se via outra idéia que não fosse montar um teatro épico.

0 teatro épico se diferencia do teatro dramático. Neste o protagonista vive um conflito pessoal e interno e o espectador se identifica com sua causa. Existe uma linha dramática na qual os acontecimentos se sucedem, como causas e conseqüências uns dos outros, chegando a um ápice. No final, feliz ou infeliz, há um apaziguamento, um retorno à ordem estabelecida³ . No teatro épico, por sua vez, o

2 Esse detalhe da dramaturgia, extraído de Woyzeck, também me remete a uma passagem da peça $O$ auto dos bons tratos, da Cia. do Latão, na qual um ferreiro do século XVI admite que, seguindo ordens, pregara uma ferradura em um índio. E se defende dizendo que o índio já era uma besta de carga antes. Sérgio de Carvalho, diretor da peça, considera que "a violência corresponde à normalidade capitalista". É normal, diante da necessidade econômica, "tratar outro homem como besta de carga" (Carvalho, 2009, 64). 0 mesmo ocorre com o personagem Francisco em Relações... Ele não é visto como um ser humano, mas sim como um instrumento sem valor e por isso seu organismo pode ser utilizado, sem qualquer preocupação com as conseqüências, em um experimento "científico". Além do mais o personagem aceita o trabalho de engraxar as botas do Capitão, durante os intervalos entre as idas ao consultório. Isto é, ele está socialmente abaixo das botas do Capitão.

3 Pavis (1999) explica que o dramático é “um princípio de construção do texto dramático e da representação teatral que dá conta da tensão das cenas e dos episódios da fábula rumo a um desenlace". Já o épico, como não se limita a um gênero, pode desempenhar um papel mesmo no interior do texto dramático, pela inserção de relatos. 0 dramático e o épico podem estar juntos em um mesmo espetáculo. 
personagem é movido por forças externas a ele, por isso é cheio de contradições. Não possui carga psicológica e é caracterizado em relação ao ambiente e aos outros personagens (por esta razão são considerados personagens-tipo, pois representam menos o indivíduo do que seu grupo social). Assim os conflitos estão fora do personagem, na relação deste com o meio.

Bernard Dort (1980, p. 209) explica: “(...) a personagem brechtiana não é uma. É feita de comportamentos contraditórios, de uma sucessão de ações e de palavras que se decifram umas pelas outras. Nunca toma forma definitiva. Mais exatamente, não pára de se nos revelar das mais diversas e complexas maneiras que podíamos imaginar, não pára de mudar, diante dos nossos olhos, segundo a situação em que se encontra." Da mesma forma, as narrativas no teatro épico são fragmentadas, episódicas, eliminando assim a idéia de uma ordem natural que move os indivíduos. Não há um ápice nem um desfecho na dramaturgia. 0 espectador, ao invés de se identificar com o personagem, julga-o conforme as condições apresentadas. A realidade representada no teatro épico não é natural. Portanto pode ser transformada. Essa é a tese do teatro épico. Tudo é resultado de como as sociedades se desenvolvem e não da natureza. Por isso, não há nada que não seja transformável. Segundo Bernard Dort (1980, p. 213) “Na representação do teatro brechtiano, o espectador descobre-se a si mesmo, mais exatamente, descobre sua própria situação na sociedade real e descobre as tarefas que lhe faltam realizar para poder ser, enfim, ele próprio." 0 teatro épico de Brecht quer persuadir as pessoas a transformar a realidade em que vivem, a não se conformar com o que parece estabelecido.

Anatol Rosenfeld (2002, p. 148) explica que o teatro épico de Brecht pretendia apresentar um "teatro científico", capaz de esclarecer o público quanto à necessidade de transformar a realidade e incitá-lo a transformar. Esse mesmo autor esclarece que o teatro épico tem como função desmistificar a idéia de "natureza humana", pois as desgraças humanas são conseqüências históricas e não naturais, como normalmente são representadas no teatro dramático. 0 ser humano não é um ser "fixo". Isso, porém, não significa que as emoções estejam fora do teatro épico. Brecht (apud Rosenfeld, 2002, p. 148) diz que as emoções não precisam ser as mesmas dos personagens.

A emoção que o teatro épico provoca vem junto com o posicionamento crítico. Para atingir este objetivo, Brecht lança mão de recursos como o efeito de distanciamento. São recursos utilizados em cena e servem para romper com a ilusão do teatro. Ao manter a consciência de que está em uma sala de teatro, e que o que está sendo visto é ficção, o espectador pode adquirir uma postura crítica em relação ao que está vivenciando. É chamado distanciamento brechtiano quando esse efeito de quebra de ilusão provoca uma reflexão que vise à tomada de atitude. Rosenfeld (2002, p. 151) acrescenta que nossa situação, época ou sociedade devem ser representadas distanciadas no tempo histórico ou espaço geográfico. Assim o público reconhecerá as situações sociais como relativas e fugazes. Enfim, para Brecht (apud Rosenfeld, 2002, p. 155), distanciar significa "ver em tempos históricos". 
0 ator brechtiano trabalha seus personagens a partir do gestus social e não do gesto individual. 0 gestus representa o corpo do personagem de acordo com seu grupo social. Isto é, o gestual do personagem é sempre comum ao grupo a que pertence. Não é individual, pois o personagem se compõe a partir de sua relação com outros personagens. Chama-se esfera do gesto aquela a que pertencem as atitudes que as personagens assumem em relação umas às outras. A posição do corpo, a entoação e a expressão fisionômica são determinadas por um gestus social; as personagens injuriam-se mutuamente, cumprimentam-se, instruem-se mutuamente etc.

0 gesto que caracterizaria o personagem individualmente (ex. como ele acorda, boceja, coça a cabeça etc.) não interessa tanto ao teatro épico e por isso não pode sobressair ao gestus. 0 gesto individual é característica do teatro dramático. No teatro épico o ator "mostra" o personagem, mantendo certa distância dele. Portanto, ele "narra" com o gestus (Rosenfeld, 2002, p. 161), que é coletivo. Relações em Conflito nos remete ao teatro de Brecht, não apenas enquanto investigação estética, mas também enquanto desejo de se fazer um teatro engajado, que nos leve a uma reflexão mais profunda sobre o ambiente em que vivemos e suas contradições. É por causa disso que as personagens não têm carga psicológica, portanto são mais identificadas como personagens-tipo, caracterizadas mais pelo gestus social, segundo a linha brechtiana.

Brecht via as condições sociais como acontecimentos em processo que provocam contradições. Consta, em seu Pequeno organon... (1967), que se movimentarmos as personagens em cena por meio de forças motrizes de caráter social, que variem conforme a época, o espectador não poderá sentir, pura e simplesmente, que agiria tal e qual; dirá: "Também eu teria agido assim"; ou, quando muito: "Se eu tivesse vivido em tais circunstâncias..." E se representarmos as peças da nossa época tal como se fossem peças históricas, será possível que ao espectador pareçam, então, igualmente, singulares as circunstâncias em que ele próprio age; nasce nele, assim, uma atitude crítica. Isto leva a perguntar-se se não haveria outra atitude possível de reação. Acreditamos, porém, que não apenas o espectador tem sua atitude crítica mais aguçada como também o educando/ator, durante o processo de pesquisa e montagem.

No caso de Relações em Conflito, procuramos, em primeiro lugar, criar personagens que fossem contraditórios, que pudessem ser ao mesmo tempo opressores e vítimas. Por exemplo, o personagem Francisco, enlouquecido por causa de um experimento científico, e por isso discriminado na comunidade, possui um sentimento paterno que o faz querer defender sua filha de uma agressão. Mas para isso se utiliza de agressão física contra um menor, o que é reprovável. As testemunhas, mesmo percebendo a injustiça, não fazem nada para combatê-la, por medo. A Professora sustenta um discurso antiviolência, mas não percebe a situação de bullying em sua sala de aula. Além disso, ela mesma emprega a palavra índio para designar os alunos indisciplinados, revelando, assim, um preconceito racial. Em sua fala, a professora revela ainda estigmas que ela própria criara: "turminha da frente, 
que só da alegria", "turminha do fundão" etc... Maria, a mãe, mostra-se afetuosa e piedosa com os jovens, mas considera tais agressões brincadeiras de crianças, revelando-se alheia à realidade. Essas características dos personagens podem provocar o senso critico do espectador. Os personagens são mostrados como desprovidos de consciência da sua realidade. São movidos por forças externas, mas essas forças são sociais e não naturais, por isso podem ser transformadas.

Sérgio de Carvalho (2009, p. 49), comentando sobre a atualidade do teatro de Brecht e a necessidade de estudá-lo, especialmente no Brasil, diz que acredita que ainda não é de conhecimento geral que as representações humanas não são naturais. Para ele "os véus ideológicos contemporâneos são muito fortes e elásticos", dando às dinâmicas do capitalismo aparência de eternas ${ }^{4}$. Assim, acreditando num fatalismo, os grupos sociais tendem a não lutar por mudanças.

Trabalhar com referências na linguagem brechtiana hoje não mais se faz romper com a organização teatral estabelecida. Muitos elementos já foram assimilados pelo teatro. Porém, a forma dramática e naturalista ainda é vista hoje, deslocada para o cinema e para a televisão, com alto poder de propagação e grau de influência igual ou maior do que o teatro naturalista tinha até o começo do século XX. Esperamos ao menos que a experiência teatral com os jovens da Tapera os tenha ajudado a ampliar sua percepção em relação ao meio em que vivem e à sua própria participação nele.

\section{Conflito e contradição}

Bernard Dort ${ }^{5}$ (1980, p. 209) explica que os personagens de um teatro épico, nos moldes de Brecht, "nunca se encontram na grande cena onde culminam e se resolvem as suas lutas. Nunca se confrontam com a sociedade num corpo a corpo decisivo". Ou seja, a noção de conflito é substituída pela de contradição. São as contradições nos comportamentos dos personagens que geram os conflitos.

Ao ser defendida pelo pai, na última cena de Relações em Conflito, a menina Juliana se livrou, naquele momento, de levar uma surra do garoto maior, mas não de sua ferida moral. Com o ato violento, o pai apenas reafirmou sua condição de doente e ela continuaria sofrendo bullying. Não há final feliz nem infeliz. Não há nenhum apaziguamento definitivo, nem mudança na ordem estabelecida. Isto é característica do teatro épico, de acordo com Dort (1980).

Como já foi dito, no teatro épico o personagem se define pela sua relação com

4 Essa observação nos remete ao pensamento de Frederic Jameson (1997), para o qual o capitalismo tardio se instalou no mundo de uma forma tal que parece inútil qualquer tentativa de combatê-lo.

5 Primeira edição em 1960. 
o meio, isto é, com os outros personagens e não pelo ator. 0 Tamboreiro-mor de Relações em conflito, por exemplo, em um primeiro momento se apresenta ao público como sendo um homem educado, sedutor, defensor do trabalho e da honestidade. Em seguida, pouco a pouco se revela perverso ao expulsar Francisco do bar, com palavras ofensivas e humilhações, só pelo fato de o outro ser pobre e não ter dinheiro para pagar sua bebida (que costumeiramente é oferecida por "conta da casa" para o próprio Tamboreiro-mor).

\section{Contradição e conscientização}

0 processo de busca do tema, resultado de uma investigação na comunidade, envolvendo os alunos, foi embasado nas idéias de universo temático e tema gerador, sugerido por Paulo Freire. Também baseados em Freire procuramos trabalhar de maneira dialógica, levando propostas, mas ao mesmo tempo abrindo espaço para que os alunos trouxessem as próprias e expressassem seus interesses.

Freire diz que os investigadores do tema gerador, nos primeiros contatos, devem reunir pessoas da comunidade, expor-lhes seus propósitos e fazer com que o número maior deles aceite auxiliar-Ihes na investigação, trabalhando junto. Deve-se também andar pela região, conversar com os moradores, fazer o máximo de anotações no seu caderno (FREIRE, 1977). É preciso participar da vida da comunidade. Foi assim que jovens da Tapera nos mostraram sua comunidade, desenharam seus caminhos e relataram suas histórias.

Ao final de cada apresentação era sempre proposto um debate com o público. Este às vezes se mostrava mais participativo, às vezes menos. 0 que normalmente se comentava era que quase sempre alguém da platéia ou familiar já sofrera alguma experiência de bullyng. 0 espetáculo também chegou a provocar comentários sobre a diferença entre as classes sociais, como um pobre é tratado ao entrar em um estabelecimento e como uma autoridade é tratada. Alguns moradores da Tapera chegaram a comentar que, até então, nunca haviam parado para pensar no quanto era forte a interferência da Base Aérea lá. Outro aspecto que surgia nos debates era que a força e a vingança não são as maneiras corretas de se resolverem os conflitos.

A intenção de fazer com os jovens da Tapera um teatro que proporcionasse uma visão mais ampla de sua realidade também se espelhou na proposta de educação trazida por Freire, a qual visa uma tomada de consciência. 0 tema bullying poderia ser trabalhado baseado no que diz Freire sobre a relação opressor-oprimido. Enquanto este não consegue localizar o opressor concretamente nem tornar-se consciente de sua condição de oprimido, assume atitudes fatalistas diante da situação em que está. Isto às vezes dá impressão de docilidade. Este fatalismo é fruto de uma situação histórica e sociológica. De tanto ouvirem que são incapazes os oprimidos acabam acreditando nisso. Somente quando descobrem, nitidamente, o 
opressor e se engajam na luta organizada pela libertação é que passam a acreditar em si mesmos, nos seus potenciais, superando o regime opressor (FREIRE, 1977). Esses foram os princípios que regeram a interferência do Núcleo de Formação de Facilitadores da UDESC na comunidade da Tapera. Espera-se que essa experiência tenha contribuído com a educação daqueles jovens. 


\section{REFERÊNCIAS BIBLIOGRÁFICAS}

> CARVALHO, Vera M.; MILWARD, Léa F. P.; ARAÚJ0, Elza M. D. Vale a Pena Fazer BRECHT. Bertolt. Pequeno organon para o teatro. In: Teatro Dialético. Rio: Civ. Brasileira, 1967.

> CARVALHO, Sérgio de (org.). Introdução ao teatro dialético: experimentos da Companhia do Latão. São Paulo: Expressão Popular, 2009.

> DORT, Bernard. Leitura de Brecht. Forja, 1980.

> FREIRE, Paulo. Pedagogia do oprimido. Rio de Janeiro: Paz e terra, 1977.

$>$ JAMESON. Fredric. A lógica cultural do capitalismo tardio. In: Pós-modernismo. São Paulo: Ática, 1997.

> PAVIS, Patrice. Dicionário de teatro. São Paulo: Perspectiva, 1999.

> ROSENFELD, Anatol. 0 teatro épico. 4š ed. São Paulo: Perspectiva, 2002.

Márcia Pompeo Nogueira, doutora, professora do Departamento de Artes Cênicas do Centro de Artes da UDESC

marciapompeo@gmail.com

Aline Porto Quites, acadêmica do Curso de Licenciatura e Bacharelado em Teatro - Centro de Artes-UDESC, bolsista de iniciação científica PROBIC/UDESC alinepq@yahoo.com.br 